SMOKES AND MIRRORS AT THE UNITED NATIONS' UNIVERSAL PERIODIC

\title{
REVIEW PROCESS
}

\begin{abstract}
Purpose: In 2006, the United Nations' Human Rights Council was tasked to establish a new human rights monitoring mechanism: the Universal Periodic Review Process. The purpose of this paper is to examine the nature of discussions held in the process, over the two cycles of review in relation to women's rights to access health care services. Design and Methodology: This investigation is a documentary analysis of the reports of 193 United Nations' state reports, over two cycles of review. Findings: The primary findings of this investigation reveal that despite an apparent consensus on the issue, a deeper analysis of the discussions suggest the dialogue between states is superficial in nature, with limited commitments made by states under review in furthering the protection of women's right to access health care services in the domestic context. Practical Implications: Considering the optimism surrounding the UPR process, the findings reveal that the nature of discussions held on women's rights to health care services is at best a missed opportunity to make a significant impact to initiate, and inform, changes to practices on the issue in the domestic context; and at worst, raises doubts as to whether the core aim of the process, to improve the protection and promotion of all human rights on the ground, is being fulfilled. Originality/Value: Deviating from the solely technocratic analysis of the review process in the existing literature, this investigation has considered the UPR process as a phenomenon of exploration in itself, and will provide a unique insight as to how this innovative monitoring mechanism operates in practice, with a particular focus on women's right to access health care services.
\end{abstract}

Keywords:

Universal Periodic Review; access to health care service; human rights dialogue; women's rights.

Article Classification:

Research Paper

For internal production use only

Running Heads: 
SMOKES AND MIRRORS AT THE UNITED NATIONS' UNIVERSAL PERIODIC REVIEW PROCESS

\section{Abstract}

Purpose: In 2006, the United Nations' Human Rights Council was tasked to establish a new human rights monitoring mechanism: the Universal Periodic Review Process. The purpose of this paper is to examine the nature of discussions held in the process, over the two cycles of review in relation to women's rights to access health care services. Design and Methodology: This investigation is a documentary analysis of the reports of 193 United Nations' state reports, over two cycles of review. Findings: The primary findings of this investigation reveal that despite an apparent consensus on the issue, a deeper analysis of the discussions suggest the dialogue between states is superficial in nature, with limited commitments made by states under review in furthering the protection of women's right to access health care services in the domestic context. Practical Implications: Considering the optimism surrounding the UPR process, the findings reveal that the nature of discussions held on women's rights to health care services is at best a missed opportunity to make a significant impact to initiate, and inform, changes to practices on the issue in the domestic context; and at worst, raises doubts as to whether the core aim of the process, to improve the protection and promotion of all human rights on the ground, is being fulfilled. Originality/Value: Deviating from the solely technocratic analysis of the review process in the existing literature, this investigation has considered the UPR process as a phenomenon of exploration in itself, and will provide a unique insight as to how this innovative monitoring mechanism operates in practice, with a particular focus on women's right to access health care services.

KEYWORDS: Universal Periodic Review; access to health care service; human rights dialogue; women's rights.

\subsection{Introduction}

In 2006, the United Nations' Human Rights Council was tasked to review member states compliance with their international human rights obligations through a novel, and unique, human rights monitoring mechanism: the Universal Periodic Review (UPR) process. The objective of the mechanism is to assess the fulfilment of human rights obligations by each state of the United Nations, via a dialogical peer review process. Each state is to be reviewed on cyclical basis, once every four years, using uniform methods (A/RES/60/251 para, 5). The first two cycles of the UPR process are now complete; the first cycle was held between 2008 and 2011, and the second between 2012- 2016. Acquiring full participation under both cycles, all member states of the United Nations have been reviewed twice under this process. The key aspect of the UPR process is the interactive discussions that are held on human rights issues among state representatives during reviews. This is a key aspect of the review process, as the commitments and explanations provided by the state representatives at the dialogue sessions can be utilised for the purposes of accountability; 
both on other international forums at the United Nations, and in the domestic context. This dialogical method of reviewing state compliance with their international human rights obligations gives the process its novel and unique character. The renowned optimism surrounding this process during its initiation (Ban Ki Moon, Office of the High Commissioner for Human Rights, 2008; KP Sharma Oli, 'Statement Honourable KP Sharma, 2006) was renewed on the $16^{\text {th }}$ June 2017 at the United Nations' Human Rights Council general debate, where it was noted that the process has enormous potential to bring real improvements on the ground (United Nations Human Rights Council: General Debate on the UPR, 2017).

In May 2017, a Report by the High Level Working Group on Health and Human Rights of Women, Children and Adolescents called for wide ranging action for the implementation of women's rights to access health care services. In light of this significant report, it is essential to reflect on how this issue has been discussed during state reviews in UPR process. The primary aim of this investigation is to examine the nature of discussions held in the process, over the two cycles of review, when the issue of women's rights to access health care services has been the centre of discussions during state reviews. The exploration is important and significant for two main reasons. First, the discussions held can be employed to hold states under review accountable for any commitments made in addressing the human rights issues and concerns that are raised by the peer states during the review. In addition, the nature of discussions can set the tone of any discussions on domestic policy changes and reforms on any particular issue. Second, the findings of this investigation will provide a unique and invaluable insight to the work and operation of the UPR process. Deviating from the solely technocratic, constitutional or state focused analysis of the review process in the existing literature (Dominguez-Redondo 2012; Jonas 2012; Abebe 2009; de Frouville 2011; de la Vega and Lewis 2011) this investigation has considered the UPR process as a phenomenon of exploration in itself, by undertaking a sustained and comprehensive analysis of the dialogues held on the issue of women's rights to access health care services over the two cycles. This analysis will provide an evaluative contribution to help understand the nature of the review process, and how this unique monitoring mechanism operates in practice, with a particular focus on women's right to access health care services.

This paper is organised in to four main sections. The first section will provide a brief overview of the mechanics and modalities of the UPR process. The second section will analyse the issue of access to health care services in the context of international women's rights law. The findings of this investigation will be presented in the third section of the paper, with the fourth section dedicated to providing a discussion on the findings of this investigation, as well as assessing its broader implications.

\subsection{Universal Participation and Dialogue as the foundational principles of the Universal Periodic Review}

Under the UPR process, each state's human rights records are assessed according to its obligations under the United Nations' Charter; the Universal Declaration of Human Rights; the United Nations human rights treaties to which the state is a party; any voluntary pledges it has made regarding human rights, including any commitments it had made during the previous cycle of review; and the principles of international humanitarian law 
(A/HRC/RES/5/1, para 3(i)). The state reviews are based on three written reports: a national report, which is submission by the state under review of its own assessment of the human rights situation (A/HRC/RES/5/1, Annex 1 section 15(a)). The other two reports are an external assessment of the state's human rights obligations. One report is based on information provided by a number of United Nations bodies, and the other report is based on submissions made by stakeholders, such as non-governmental organisations (NGOs), or other national human rights institutions (NHRIs) (A/HRC/RES/5/1, Annex 1 section $15 \mathrm{~b}$ and c). State representatives are invited to consult these reports and to devise questions and recommendations that are to be directed to the states under review at the key stage of the review process: the interactive dialogue session. Formally, each state review in the UPR process is undertaken by the UPR Working Group, which consists of the 47 member states of the United Nations Human Rights Council. However, at the interactive dialogue stage, any member of the United Nations can take the stage to comment, ask a question or issue a recommendation to the state under review in relation to any human rights issue. In response, the state under review is obligated to provide an instantaneous reply (A/HRC/PRST/8/1, para 4). Following the discussions, a Final Outcome Report is produced, which consists of all the comments, recommendations and responses issued during the interactive dialogue stage of the review ( $A / H R C / R E S / 5 / 1$, Annex 1 , section 27). The recommendations that enjoy the support of the state under review are identified as being 'accepted' and those recommendations that do not are 'noted' (A/HRC/RES/5/1, para 32). In this way, formally, no recommendations are recorded as 'rejected' by the state under review, despite the essence the statements indicating otherwise. It is to be noted, that for the second cycle of review, the terminology for those recommendations that were accepted has been changed to being 'supported'.

The interactive dialogue session plays a fundamental role in determining the extent to which the UPR process meets its ultimate aim to further the promotion and protection of human rights (A/HRC/RES/5/1, para 3 (a)). The instantaneous nature of the dialogue session generates an expression of commitment by the state under review to an action being suggested by an observer state on any human rights issue. Considering the prominent role of civil societies, national human rights institutions, and other relevant stakeholders in the UPR process, the commitment expressed by the state under review during the dialogue can not only be used to review the state's progress in the next cycle of review; but can also be used as a tool by civil society and other relevant stakeholders to hold states accountable in the domestic context. In addition, the political momentum generated amongst the discussions held on particular issues can create lucrative avenues to influence or facilitate domestic legal, social and policy reforms in the state under review. In this way, the discussions held on women's rights to access health care have a role beyond the implementation and monitoring of rights, but can also set the tone in the coordination and plans for reforms in the domestic context. On completion of the review, the state under review has the primary responsibility to implement the recommendation prior to its next cycle of review.

\subsection{International Human Rights Law on Women's Rights to Access Health Care Services}


For the purposes of this section, women's rights to access health care services includes information and services made available by health authorities such as preventative medical care, reproductive choices, screening procedures, dietary factors (Rebecca Cook, 1998). This right is guaranteed under Article 12 of the International Covenant on Economic, Social and Cultural Rights, which contains four interrelated elements, which include the accessibility of health care facilities (CESCR General Comment No: 14). On women's rights more specifically, the Committee on the Convention to Eliminate all forms of Discrimination against Women have directed member states to take appropriate measures to enable women to 'access health care services, including those related to family planning...and pregnancy' (CEDAW General Comment No: 24). In fact, the Committee on the Women's Convention has recommended that states should remove "all barriers to women's access to health services, education and information, including in the area of sexual and reproductive health" (CEDAW General Comment No: 24 para 31(b) and 13). Despite these repeated assertions on state obligations in relation to this right, women continue to face impediments, often not necessarily due to the lack of availability of health care services. On the contrary, the lack of protection is frequently based on the traditionally perceived role of women in the private sphere, which often results in women's access to health care being more susceptible to restrictions that are founded on cultural values and norms (Raday, 2003). For instance women are sometimes prevented from controlling their own fertility; are subject to nutritional taboos and traditional birth practices (UN Commission on Human Rights, 2002) and prevented from accessing scientific medicine in favour of traditional remedies during pregnancy; all of which sometimes result in long term harm or fatality (UN OHCHR, 1995). Writing on this complex issue of cultural barriers that impede women's access to health services, Radhika Coomaraswamy explains women's primary duty is to reproduce, and therefore, any health consequences from the process of childbirth are often explained by fate, destiny and social and cultural practices, rather than a violation of women's rights to health services (UN OHCHR, 1995). For the purposes of this investigation, the focus will be on the discussions on this issue amongst states, and how the states are held accountable for implementing this right.

\subsection{Research Method and Methodology}

Due to the nature of this investigation, a note on the methods and methodology adopted for the purposes of this exploration is warranted. This section will the method of analysis adopted and summarise how the author reached the conclusions of this investigation.

This exploration is a documentary analysis of the reports produced for the states reviews of all 193 member states of the United Nations for the purposes of the UPR process. At the conclusion of each state review, a Final Outcome Report, and Addendums (if any), are produced, which provides the statements made by observer states and the states under review during the interactive dialogues state of the review process. For the purposes of this investigation, the primary data collection was extrapolated for analysis from these reports for each member states for the two cycles of review in the UPR. Once the data was identified, the Qualitative Content Analysis (QCA) approach was used to describe and analyse the meaning of the qualitative material in a systematic way to address the aims and 
objectives of a study (Margrit Schreier, 2012). When undertaking documentary analysis, there are two main methods of content analysis: manifest and latent content analysis. The manifest content analysis restricts the analyses on entirely 'the surface meaning of text', as the focus is on those elements that are physically present in the content of the data (Berg 2007; Holsti, 1969). Instead, I adopted a latent context method of analysis to which extends to an interpretative reading of the text and focuses 'on the deep structural meaning conveyed by the message (Berg, 2007). This method is used to 'analyze the deeper layers of meaning embedded in the document' (Holsti, 1969). The latent content analysis is therefore 'extended to an interpretative reading of the symbolism underlying the physical data' (Berg 2007) .This in-depth method of analysis allowed the investigation to go beyond the literal and face value of the discussions held on the UPR process, to underlying and implicit meanings of the positions adopted by states during the reviews to enable a deeper understanding of the UPR process, and how the issue of women's right to access health care services was discussed during state reviews over the two cycles.

\subsection{Findings on how women's rights to access health care services was discussed during state reviews}

Over the two cycles of the UPR process, a total of 134 recommendations were issued to 103 member states on women's right to access health care services over the two cycles of review. Of these, the issue was raised during the reviews of 47 states in the first cycle, which increased to 56 states in the second cycle of review. Of the 134 recommendations issued, only 13 were noted. This suggests, at least formally, there is a consensus amongst the majority of states that were reviewed in the UPR process on the universal nature of women's rights to access health care services.

For the purposes of clarity, and to aid analysis for this investigation, the statements issued during the interactive dialogue sessions have been divided into a number of categories. $\mathrm{A}$ summary of the discussions held on access to health care services, over the first and second cycles of review is encapsulated in Figure 1 and Figure 2, respectively. The statements issued during the interactive dialogue sessions can be divided into to two main categories: first, recommendations by the observer states, and second the responses provided by the state under review when supporting or noting the recommendation. In the first cycle, as depicted in Figure 1, the nature of recommendations of access to health care services are divided into 3 main categories, which can be found toward on the rows toward the left of Figure 1. In the second cycle, there were only two types of recommendations issued; these are noted in the rows toward the left in Figure 2. The nature of responses divided into categories can be found in the columns across the top of Figures 1 and 2, shaded in blue. The nature of responses are divided into 6 different categories for the first and second cycle. Each of the 6 categories for both cycles can be further divided into 2 main categories; those recommendations that were supported have been abbreviated with an S; and those noted with an $N$. The number following ' $S$ ' and ' $N$ ' can be identified with a summary of the nature of the statements issued with the responses during the discussions. 


\section{Page 7 of 25}

International Journal of Human Rights in Healthcare 
(Accepted recommendation with no further comments)

\begin{tabular}{c|c} 
A2 & A3 \\
(Domestic & (Information on
\end{tabular}

laws already

implemented/

under review)

measures and

policies that are

A5

N1

N2

Recommendation 1

(Generic

tions issued to

recommendations on

states under access to health care

services) 


\begin{tabular}{|c|c|c|c|c|c|c|}
\hline \multirow{2}{*}{\multicolumn{2}{|c|}{$\begin{array}{l}\text { Universal Periodic Review Cycle } \\
2\end{array}$}} & \multicolumn{5}{|c|}{ Responses by the states under review } \\
\hline & & $\begin{array}{c}\text { S1 } \\
\text { (Accepted recommendation } \\
\text { with no further comments) }\end{array}$ & \begin{tabular}{l}
\multicolumn{1}{c}{ S2 } \\
(Information on measures and \\
policies that are already in \\
place)
\end{tabular} & $\begin{array}{c}\text { N1 } \\
\text { (Noted } \\
\text { recommendations } \\
\text { with no further } \\
\text { comments) }\end{array}$ & $\begin{array}{c}\mathbf{N 2} \\
\begin{array}{c}\text { (Policies already in } \\
\text { place) }\end{array}\end{array}$ & $\begin{array}{c}\text { N3 } \\
\text { (Denial of any } \\
\text { discrimination on grounds } \\
\text { of gender) }\end{array}$ \\
\hline \multirow[t]{2}{*}{$\begin{array}{l}\text { Nature of } \\
\text { Recommendation } \\
\text { s issued to states } \\
\text { under review }\end{array}$} & \begin{tabular}{|l|} 
Recommendation 1 \\
(Generic \\
recommendations \\
on access to health \\
care services)
\end{tabular} & $\begin{array}{l}\text { Afghanistan/Albania/Andorra/C } \\
\text { roatia/Cyprus/DPR } \\
\text { Korea/Democratic Republic of } \\
\text { Congo/Ecuador/El } \\
\text { Salvador/Ethiopia/Guinea/Iran/ } \\
\text { Kyrgystan/Malawi/Malaysia/Ne } \\
\text { pal/Niger/Republic of } \\
\text { Congo/Romania/Saudi } \\
\text { Arabia/Somalia/St Vincent and } \\
\text { the Grenadines/Yemen }\end{array}$ & $\begin{array}{l}\text { Benin/Central African } \\
\text { Republic/Chile/Comoros/Gam } \\
\text { bia/Georgia } \\
\text { /Hungary/Lesotho/Macedonia } \\
\text { /Madagascar/Maldives/Micro } \\
\text { nesia } \\
\text { Morocco/Namibia/Peru/Philip } \\
\text { pines/Senegal/Sierra } \\
\text { Leone/Singapore/Tajikistan/T } \\
\text { hailand/Uzbekistan }\end{array}$ & Lebanon & $\begin{array}{l}\text { Antiqua and } \\
\text { Barbuda } \\
\text { Papua New Guinea }\end{array}$ & Kuwait \\
\hline & $\begin{array}{l}\text { Recommendation } 2 \\
\text { (Amend/Reform/Im } \\
\text { plement law to } \\
\text { protect women's } \\
\text { rights to access } \\
\text { health care } \\
\text { services) }\end{array}$ & & Bangladesh & & Nicaragua & Myanmar \\
\hline
\end{tabular}

Figure 2: Discussions held on Women's Right to Health Care in the Second Cycle of the UPR process 


\subsubsection{Recommendation 1: Generic recommendations on access to health care}

Under this category of recommendations, observer states instructed states under review to ensure that women were provided with adequate access to health care services. The nature of the recommendations can be described as being generic in nature, as observer states did not make any references to the states international obligations in the suggestions made, or provide any specific guidance as to the laws or polices that should be implemented. Instead, the observer states simply raised concerns, or made suggestions, that women should be provided with access to health services. Encapsulating the essence of this recommendation, during the review of Andorra, the Chinese delate recommended to improve policy on healthcare and provide affordable health care services to women' (UNHRC, 'Andorra' 2010 $\mathrm{A} / \mathrm{HRC} / 13 / 16$, para 84.66). Recommendations of this nature was the most prevalent in both the first and second cycles of review as it was raised during the review of 90 member states in the first and second cycle of reviews.

When issued with this recommendation, in the first cycle of review, the overwhelming majority of states accepted this recommendation. In particular, a total of 23 states accepted without any further comments, thus being the most prevalent response under category one recommendations. The other states that accepted the recommendation drew references to existing laws and policies that were already in place to ensure women have access to health care services. A typical example is the response of Bolivia who stated that 'the Plan of Sexual and Reproductive Health...is being implemented to respond to the needs of the population, especially women...Bolivia has strengthened its integral healthcare.' (UNHRC 'Bolivia (Plurinational State of $2010 \mathrm{~A} / \mathrm{HRC} / 14 / 7$, para 55.). The delegate of Afghanistan was the only state that provided a combined $A 2$ and $A 3$ response as it was stated that the right to health was enshrined in the constitution, and that polices were already in place to expand the public health service and improve maternal health. (UNHRC 'Afghanistan' 2009 $\mathrm{A} / \mathrm{HRC} / 12 / 9$, para 89). On the other hand, the states of Malta, Mexico and Suriname refused to accept the recommendation and, instead, noted them without any further explanation. In contrast, the delegate of Bosnia and Herzegovina provided an explanation with its refusal to accept the recommendations by stating that 'gynaecological services at the primary, second and tertiary levels of health care during pregnancy, child birth and after childbirth and other health services are available to meet the needs of women' (UNHRC, 'Bosnia and Herzegovina' 2010, A/HRC/14/16 para 6).

Similar to the first cycle, in the second cycle of reviews, recommendations under the first category were most frequently issued, and the most prominent response was to accept the recommendation without any further explanation. A total of 22 states provided a S2 response, whereby states made references to existing policies that are in place to ensure women have appropriate access to health care services. An example is when the delegate of Comoros responded by referring to the government's existing health policies and stated that 'huge priorities had been made in ensuring vulnerable persons have access to health care' (UNHRC, 'Comoros' 2014, A/HRC/26/11, para 70). In contrast, the states of Lebanon, Antiqua and Barbuda, Papua New Guinea and Kuwait noted the recommendations under this category. Of these, Lebanon noted the recommendation without any further 
comments. The states of Antiqua and Barbuda Papua New Guinea, whilst noting the recommendations, made references to existing health policies in place; the delegate of Papua New Guinea explained that 'health for women is supported and promoted at all levels in the country' (UNHRC, 'Papua New Guinea' 2016, A/HRC/33/10/Add.1). Providing a more defensive response, Kuwait noted the recommendation and explained that 'all persons, without distinction on the basis of gender, enjoy equality in relation to healthcare' (UNHRC, 'Kuwait' 2015, A/HRC/29/17/Add.1).

Overall, it can be observed that when states were issued with a recommendation under this category, the majority of the states responded by accepting it, and then providing no further comments or referring to existing policies and measures in place to guarantee women's rights access health care. In addition, aside Kuwait, the states that noted the recommendations either provided no further comments, or referred to existing policies and measures in place to guarantee access to health care for women.

\subsubsection{Recommendation 2: Amend/Reform/Implement law to protect women's rights to access health care services}

Under this category of recommendations, the observer states instructed the states under review to reform domestic legislation to guarantee women's rights to access health care services. The nature of these recommendations is captured during the review of Myanmar, when the delegate of Canada issued a recommendation to 'Repeal and Amend Bill on Population Control and Health care Bill...and ensure respect for the human rights of women' (UNHRC 'Myanmar' 2015, A/HRC/31/13 para 145.19).

In the first cycle of the UPR process, a total of 5 states were issued with a recommendation of this nature; all of the states in question accepted this recommendation. The states of Angola, Nicaragua and Timor Leste accepted the recommendation without any further comments, whilst the delegate of El Salvador made reference to existing polices and measures that were already in place (UNHRC, 'El Salvador' 2014, A/HRC/28/5). On the other hand, the delegate of Paraguay adopted a distinguished position. The delegate began by stating that the government had taken initiatives focusing on the implementation of women's right to health; it then went on to add that Paraguay 'expects to achieve a significant reduction in the existing cultural, geographic and economic barriers that hinder access to health services (UNHRC 'Paraguay, Addendum' 2011, A/HRC/17/18/Add.1 para 13). The nature of this response is significant as it is the first, and only time, in the two cycle of reviews that whereby a state has recognised the significance of cultural barriers that can potentially impede women's rights to access health care services.

In the second cycle, this recommendation was only issued during the reviews of 3 states. Bangladesh was the only state that accepted the recommendation, and provided information on existing policy measures that were in place to address the issue (UNHRC, 'Bangladesh' 2013, A/HRC/24/12). In contrast, Nicaragua noted the recommendation stating that 'the national strategy on sexual and reproductive health established strategic objectives' in relation to women's health (UNHRC 'Nicaragua' 2014, A/HRC/27/16). The state of Myanmar also noted the recommendation, and explained that the objective of the 
law on health protection and coordination regarding population increase was to reduce poverty and promote maternal and child health' (UNHRC, 'Myanmar' 2015, A/HRC/31/13). Overall, it can be observed that when the states under review were issued with a recommendation of this nature, the responses varied significantly over the two cycles of review.

\subsubsection{Recommendation 3: References to states' international obligations}

Observer states that issued recommendations under this category drew upon the international human rights obligation of the state under review when making suggestion to ensure that women's rights to access health care services were protected. A typical example is when the delegate of Netherlands issued a recommendation to Belize to 'take further concrete measures to enhance women's access to health care...as recommended by the Committee on the Elimination of Discrimination against Women' (UNHRC, 'Belize' 2009, $\mathrm{A} / \mathrm{HRC} / 12 / 4$ para 35$)$. This type of recommendation was only issued in the first cycle of review, and was issued to a total of 8 states. In response, 7 states accepted the recommendation without any further comments. The only state that noted the recommendation was Israel, who provided no further explanation. Recommendations issued under this category were overwhelming accepted, and the one state that noted the recommendations refrained from issuing any further comments.

\subsection{Discussion on the Findings of Polygamy in the First and Second Cycle \\ of the UPR Process}

Over the two cycles of review, just over $90 \%$ of all recommendations issued in relation to women's rights to access health care services were accepted. Based on the large numbers of acceptances of the recommendations on the issue, in the first instance, one may conclude that, as least formally, states share a consensus on the protection of women's rights to access health care services, and to take appropriate action in the domestic context to ensure that this right is guaranteed. However, on closer examination the nature of discussions held on the issue indicate that the apparent consensus veils the unfruitful dialogue that is held on the issue during state reviews. In light of this, it is argued that complex and multifaceted issues, particularly in relation to cultural barriers that women face in accessing health care services, were largely absent during the discussions amongst states in the two cycles of review. There are three main themes that have emerged from the nature of discussions that have been held on women's rights to access health care services over the two cycles of review. Each theme will be discussed separately, with a final section analysing the implications of these findings for the UPR process, and the protection of rights in the domestic context.

\subsubsection{Recommendations lacked detail and rigour}

In the two cycles of review, the majority of the observer states when discussing women's rights to access health care services adopted positions by issuing recommendations that were generic in nature. Despite the apparent positive outcome with the majority of these recommendations being accepted, on closer examination, the recommendations lacked 
rigour and potency in suggesting significant reforms to be implemented to ensure that women were guaranteed to have sufficient access to health care services. In fact, the nature of the recommendations were so generic, that the suggestions made to implement rights were almost trivial. The issuance of these recommendations is problematic as its generic nature means that the states under review are not directed to implement any specific and significant policies in the domestic context to ensure that women are provided adequate protection of their right to access health care. Going further, the lack of clear and detailed set of actions in these recommendations means that despite the wide ranging acceptance, it is difficult to measure the extent to which the recommendations have been implemented both in the national and international context, and in particular, the future cycles of the review process.

As stated in its initiating resolution, at the heart of the process is the aim to improve human rights issues and concerns in the domestic context. This is primarily because the lack of clarity in the actions to the undertaken by the states under review, in the most frequently cited recommendations, results in uncertainty in not only how the states under review should held accountable for issues in relation to women's right to health care, but more confusingly, it is not clear what the very nature of the actions that are required to be undertaken. In light of this, it is difficult to comprehend if, or how, any improvement are likely to be undertaken, by the states under review, in relation to access to health care services as a result of the review undertaken in the UPR process.

\subsubsection{Responses that avoided accepting commitments}

When the issue of women's right to health was the focus of discussions during state reviews, the most frequent position adopted by states under review in response to recommendations was to accept the recommendation. However, a more detailed examination of the positions adopted by states indicates a less positive outcome. For instance, the majority of the state accepted the recommendation without any further explanations. The absence of any further comments by the states in the overwhelming number of instances on the issue firstly indicates unfruitful discussions between the states on further guaranteeing access to health care services for women, which is the sole purpose of the interactive dialogue. Further, the failure to provide a clear response by the states under review means that whilst the recommendations is accepted, it is not clear how it will be implemented in practice in the domestic context. As a result, will any progression on the implementation of recommendation be difficult to monitor, but in addition, it gives reason to doubt whether any substantial or comprehensive reforms will be implementing to better guarantee the right for women.

The second most frequent position provided by states under review in response to recommendations on women's right to access health care services was that whilst accepting the recommendation, information was provided existing measures and polices on the issue were already in place. This response was frequently issued in relation to the generic recommendations and El Salvador and Bangladesh adopted this response when suggested to reforms domestic to ensure better protection of the right. However, it can be noted that far more states responded in the second cycle by providing information on measures that 
were already in place. In this way, it can be argued that when generic recommendations were made in the second cycle, states were far more defensive in comparison to the first cycle as rather than remain quiet on the issue they chose to provide information on the policies in place to provide the protection. These positions adopted by states under review results in an unfortunate outcome. Whilst it is clear that the issue of women's right to health is clearly, to some extent, an issue of concern, the state under review has failed to adopt any new commitments or policy initiatives to ensure better protection of women's rights to access health care. In fact, the reference to existing policies would suggest that there is a fair possibility of the lack of any further initiatives will be taken in the domestic context to provide better protection of the right. In this way, unfortunately, there is little in terms of substantial outcome from the UPR process, whereby the states have expressed commitments to reforms or implement new practice to better guarantee the protection.

The subdued nature of responses continued even when the states under review noted the recommendations issued to them. In fact, in all instances when states noted recommendations on the issue, the responses have been one of the three; to not provide any further explanation, to refer to existing practices or to deny the existence of any form of discrimination on gender. The ramifications of the subdued and defensive positions has resulted in these states not accepting any concrete commitments resulting from the review. This gives reason to question one of the fundamental promises of the review process, which is to improve human rights on the ground through encouraging further promotion and protection of rights through the UPR process. The reason to question is aim is based on the overtly subdued nature of responses by the states under review. This has resulted in a lack of a formal outcome from emanating from the review process, as, in the majority of cases, the states under review do not provide clear indication as to the nature of the actions that will be implemented to improve women's access to health care services at domestic level. In this way, the aim of improving human rights on the ground is both difficult to implement, and will be particularly challenging to measure in the third cycle reviews.

\subsubsection{Lack of consideration of cultural barriers}

The state of Paraguay provided a distinguished response when issued with recommendations to amend existing laws and policies to ensure guarantee of women's right to access health care services. It is the only state in over nearly a decade of discussions on women's right to access health care in the UPR process, who recognised the significance of cultural barriers in women's rights to access health care and endeavoured to remove them. No other states, whether in their capacity as an observer state or state under review, recognised the possibility of cultural barriers potentially hindering women's rights to access health care services. This shows that despite the concerns raised in the academic literature of the cultural influenced barriers that women may face in accessing health care services, states when undertaking reviews or being reviewed in the UPR process largely failed to recognise the cultural norms and values that may impeded women's right to access health care services.

There are two significant implications of states largely failing to recognise the association between culture and women's rights to access health care services during the discussions 
held over the two cycles of review in the UPR process. The first is a practical implication, as the nature of discussions held on the issue, during the state reviews, can be described as superficial and surface level. This is because some of the underlying and significant reasons as to why women are restricted from accessing health care services were not even raised during the discussions, far from being addressed.

The second implication is interconnected to this point, as a deeper and more problematic implication is revealed. The discussions held in the UPR process, which aside once instance, overlooks the relationship between culture and the access to women's rights to health care services. This is problematic for the following reasons. For those observer states that are undertaking the review, they have, unintentionally or intentionally, adopted the polarised position of strict universalism, in the implementation of international human rights norms. Those holding a strict universalist stance on the implementation of international human rights law are of the belief that there existed a reasoned and identifiable moral order, which precedes any social and historic moral contingency (Donnelly 1998). On these grounds, the strict Universalist claim that the implementation of international human rights norms should transcend any cultural boundaries and particularities (Sloane 2001). This central belief of the strict Universalist claim is reflected in the positions adopted by the observer states, who have unanimously failed to draw upon any cultural particularities when reviewing the states in relation to the issue of women's access to health care services. It is this underappreciation of culture in the implementation of human rights has exposed this strict Universalist claimed to criticism by a number of scholars from various different perspectives (Adamantia Pollis and Peter Schwab, 1980; Dembour 2001; Renteln 1990, 2013; An-Na'im 1990; Lenzerini 2014; Merry 2003; Zwart 2012; Obermeyer 1995; Falk 1995).

The criticism of the strict universalist position that is most applicable to the present analysis of UPR process is that the overwhelming isolation of the notion of culture from the discourses on international human rights law during the discussions in the UPR overlooks the benefits of achieving cultural legitimacy in the implementation of human rights law. Advocated by a number of scholars, the aim of achieving cultural legitimacy of human rights norms identifies the merits of cultural support in furthering the implementation of international human rights in the local context. (An-Naim 1995; Zwart 2012; Merry 2006; Falk 1995; Lenzerini 2014). Cultural legitimacy is the belief that international human rights norms are more likely to achieve authority and reverence by members of a particular culture, if they are considered to be validated by the culture norms and principles, and also bring benefits to the members of the culture (An'Naim, 1990). In this regard, cultural norms and values are considered to be both open, and subject, to changes and reforms (Ibhawoh, 2000). In fact, An'Naim has suggested that the permeable nature of cultural norms can be utilised to support and ultimately enhance the implementation of human rights protection (An'Naim 1995). In this way, the absence of consideration of culture in the discussions held on women's right to access to health care is a missed opportunity to undertake a deeper and meaningful reviews of the rights, with a clear endeavour to provide better protection of this right for women. For this reason, the state representatives during the reviews should adopt a more audacious position in driving the focus of discussions toward been on addressing cultural norms that act as a barrier to women's right to health care addresses the 
very heart of the restrictions on this right. Going further, peer state representatives should undertake a more rigorous research prior to the interactive dialogue stage. This will enable the state representatives to be in a stronger position to undertake more ambitious and fruitful task to seek to embed the recommendations of any reform in recognised cultural norms beliefs in the domestic context. Such culturally legitimate recommendations to further improve women's rights to access health care services are more likely to be accepted by both the state representative and those individuals within the state (An-Naim 1995; Zwart 2012; Lenzerini 2014).

Consequently, the overwhelming isolation of the concept of culture during the states reviews in the UPR process is a missed opportunity to commence discussions on acquiring cultural legitimacy of women's rights to access to health care services on an international platform. This absence by states in exploring the complex cultural barriers that often impeded women's access to health care services is disappointing, particularly as it was expected that the dialogical and peer review nature of the review process was an apt platform to raise and discuss controversial and complex issues (Frederick Cowell and Angelina Milon, 2012).

\subsection{Conclusion}

There are two main conclusions that emanated from the findings and analysis of this investigation. First the rather stalemate, generic and subdued nature of discussions on the issue gives reason to question whether any substantial changes will be implemented in the domestic context following the state review in the UPR process. This gives reason to question whether one of the fundamental aims of the UPR process, to improve the human rights situation on the grounds, is being fulfilled. This is primarily because beyond the apparent consensus on the issue, a detailed examination of the discussions reveals a lack of rigour in the issuing recommendation on women's rights to health, and the response of accepting or noting the recommendation with no explanation or referring to existing laws was the most frequent nature of dialogue discussions held on the issue of women's rights to access health care over the two cycles of reviews. Thus, regardless of whether the recommendations are noted or accepted by the state under review, the implications are that under both instances, no reforms are agreed to be undertaken in relation to the issue as an outcome of the UPR process. For this reason, the fulfilment of the fundamental aim of the UPR process to improve the human rights situation on the ground can be called into question.

This rather stalemate and subdued nature of the discussions held on the issue have much broader and serious ramifications for the issue of access to health care services for women's rights. As noted above, the dialogue session of the UPR process forms a core part of the review process; however, beyond that, the discussions held during state reviews are formally adopted as the outcome of the UPR process for each state review. In this way, the nature of discussions and recommendations held on a particular issue can be used as advocacy tools by civil society and other relevant stakeholders to inform domestic discussions on policy reforms and implementations. Any political momentum that is generated by the discussions held during state reviews in the UPR process can create 
avenues for participation by relevant stakeholders to initiate or inform coordination to further the guarantee access to health care services for women. Thus, the tone and demeanour of discussions held in the UPR process becomes critical in the development of the direction and tone of any policy reforms in the domestic context. For this reason, it is essential that observer states do not shy away from their role as a peer reviewer in ensuring that the nature of discussions is rigorous in raising the issues of concerns, and that the recommendations instruct the states under review with clear and detailed actions on how to improve women's right to health care services. In this way, observer states should use the diplomatic and political influences to ensure that the states under review accept clear commitments in relation to women's rights to access health care services, which can be measured and to which the state under review can be held accountable both in the domestic context by relevance stakeholders, but also, in the next cycle of reviews.

The second conclusion of this investigation is the lack of rigour and constructive dialogue on an international platform of the UPR process has a broader implication. Possibly the most penitent observation from the discussions held on women's right to access to health care services the overwhelming oversight of the appreciation of the significance of culture in relation to women's right to access to health care services. There was a clear absence by peer states to draw upon the significance of culture in the discussions held on the issue. This is clearly a missed opportunity in recognising the merits of the concept of culture being incorporated into discussions of international human rights law on an international platform. The interactive dialogue element of the review process is provides an apt opportunity for states to initiate discussions to achieve cultural legitimacy on women's right to access health care services, and improve its implementation in the domestic context. Rather than engaging in a meaningful and fruitful dialogue on what the possible impediments of women's access to health care services are, and how they can be overcome, the state resorted to simplified and surface level discussions on the issue. In this way, the unique characteristics of an interactive discussions on the review process was a missed opportunity to potentially set the tone of discussions on the issue in the domestic context; or be used as a tool the civil society to initiate or inform policy changes on the ground.

In light of this, lessons should be learned by both observer states and states under review on the discussions held on the issue. States should take initiative in undertaking relevant research and consultation with stakeholders on how the concerns in relation to women's right to access health services on the particular state under review. States should draw upon culture as part of their discussions during state reviews, to both draw addresses to the challenges of cultural barriers in implementing women's right to access health care services, as well as suggesting reforms in a manner that is cultural legitimacy to ensure a better chance of improving the implementation of this right in the domestic context. Considering the optimism surrounding the UPR process when it was first established both in the academic world and the United Nations, an assessment on the how women's rights to access health care services is discussed over the past two cycles of the review process is at best a missed opportunity to make significant impact to initiate and inform changes to practices on the issue on the ground; and at worst, question whether its core aims to 
improve the protection and promotion of all human rights on the ground is in fact being fulfilled.

\section{References}

Abebe A. M (2009) Of Shaming and Bargaining: African States and the Universal Periodic Review of the United Nations Human Rights Council. Human Rights Law Review 9: 1- 35 An-Na'im A (1990) Problems and Prospects of Universal Cultural Legitimacy for Human Rights. In An- Na'im and Deng (eds), Human Rights in Africa: Cross Cultural Perspectives. Brookings Institution, Washington.

A-Na'im A (1995). Toward a Cross Culture Approach to Defining International Standards of Human Right: The Meaning of Cruel, Inhuman or Degrading Treatment. In Abdullahi AnNaim (ed) Human Rights in Cross Cultural Perspectives: A Quest for Consensus (University of Pennsylvania Press, Pennsylvania.

Berg B (2007) Qualitative Research Methods for Social Sciences. Allyn \& Bacon, United States of America.

Cook R, 'Women's Health and Human Rights in Afghanistan' (1998) 4 Journal of American Medical Association 19.

Cowell $\mathrm{F}$ and Milon A, 'Decriminalisation of Sexual Orientation through the Universal Periodic Review' (2012) 12 Human Rights Law Review 341, 34

Dembour M (2001) Following the movement of a pendulum: between universalism and relativism. In Jane Cowan, Marie-Benedicte Dembour and Richard Wilson (eds). Culture and Rights: Anthropological Perspectives. Cambridge University Press, Cambridge

Domínguez-Redondo E (2012) The Universal Periodic Review - Is There Life beyond Naming and Shaming in Human Rights Implementation. New Zealand Law Review 4: 673- 706.

Donnelly J (1998) International Human Rights. Cornell University Press, New York.

de Frouville O (2011) Building a Universal System for the Protection of Human Rights: The Way Forward. In M Cherif Bassiouni and William Schabas (eds) New Challenges for the UN Human Rights Machinery. Intersentia, Cambridge.

de la Vega C and Lewis T (2011) Peer Review in the Mix: How the UPR Transforms Human Rights Discourse. In M Cherif Bassiouni and William Schabas (eds) New Challenges for the UN Human Rights Machinery. Intersentia, Cambridge : 353-384. 
Falk R (1995 Cultural Foundations for the International Protection of Human Rights. In A.A. An-Na'im (ed), Human Rights in Cross Cultural Perspectives. University of Pennsylvania Press, London.

Holsti R (1969) Content Analysis for the Social Sciences and Humanities. Addison-Wesley, California.

Ibhawoh B (2000) Between Culture and Constitution: Evaluating the cultural legitimacy of human rights in the African State. Human Rights Quarterly 22: 838-860.

Jonas O (2012) Reflections on the Practices and Experiences of African States in the African Peer Review Mechanism and the Universal Periodic Review System. Comparative and International Law Journal of Southern African 45; 428- 453.

Lenzerini F (2014) The Culturalization of Human Rights Law. Oxford University Press, Oxford Merry S E (2003) Human Rights Law and the Demonization of Culture (And Anthropology along the way) PoLAR 26: $55-76$.

Obermeyer C (1995) A Cross-Cultural Perspective on Reproductive Rights. Human Rights Quarterly 17: $366-381$.

Oli KP, 'Statement by Honourable KP Sharma Oli to the $1^{\text {st }}$ Session of the Human Rights Council'(Geneva. 19 June 2006)<http://www.ohchr.org/Documents/HRBodies/HRCouncil/RegularSession/Session1/H LS/nepal.pdf > accessed $31^{\text {st }}$ August 2015.

Pollis A and Schwab P (1980) Human Rights: A Western Construct with Limited Applicability. In Adamantia Pollis and Peter Schwab (eds) Human Rights Cultural and Ideological Perspectives Praeger; New York.

Raday F, 'Culture, religion, and gender' (2003) 1 International Journal of Constitutional Law 663

Renteln A (1990) International human rights: universalism versus relativism. Sage Publications, London.

Sloane R (2001) 'Outrelativising Relativism: A Liberal Defence of the Universality of International Human Rights. Vanderbilt Journal of Transnational Law 34: 527- 598

Schreier M (2012) Qualitative Content Analysis in Practice. London. Sage Publications

UN Committee on Economic, Social and Cultural Rights (CESCR), 'General Comment No. 14: The Right to the Highest Attainable Standard of Health (Art. 12 of the Covenant)' (11 August 2000) E/C.12/2000/4, para 9.

UN Committee on the Elimination of Discrimination Against Women, 'CEDAW General Recommendation No. 24: Article 12 of the Convention (Women and Health)' (1999) A/54/38/Rev.1, chap. I, para 29. 
United Nations Human Rights Council: General Debate on the UPR, 2017). http://unog.ch/unog/website/news_media.nsf/(httpNewsByYear_en)/F1B7DA6246806513C 1258141004FBA0C?OpenDocument

UN Commission on Human Rights, 'Cultural practices in the family that are violent towards women' E/CN.4/2002/83, para 94

UNHRC 'Afghanistan' 2009 A/HRC/12/9, para 89

UNHRC, 'Papua New Guinea’ 2016, A/HRC/33/10/Add.1

UNHRC, 'Kuwait' 2015, A/HRC/29/17/Add.1

UNHRC 'Myanmar' 2015, A/HRC/31/13 para 145.19

UNHRC, 'El Salvador' 2014, A/HRC/28/5

UNHRC, 'Bangladesh' 2013, A/HRC/24/12

UNHRC 'Nicaragua' 2014, A/HRC/27/16

UNHRC, 'Myanmar' 2015, A/HRC/31/13

UNHRC ‘Bolivia (Plurinational State of 2010 A/HRC/14/7, para 55

UNHRC 'Paraguay, Addendum' 2011, A/HRC/17/18/Add.1 para 13

UNHRC, 'Belize' 2009, A/HRC/12/4 para 35

UN General Assembly, 'Human Rights Council’ (15 March 2006) A/RES/60/251.

UNHRC 'Res 5/1 Institution-building of the United Nations Human Rights Council' (18 June 2007) Annex (A/HRC/RES/5/1)

UN OHCHR 'Fact Sheet No. 23, Harmful Traditional Practices Affecting the Health of Women and Children' (August 1995), para 89

UNHRC, 'Bosnia and Herzegovina' 2010, A/HRC/14/16 para 6

Report of the High-Level Working Group on the Health and Human Rights of Women, Children and Adolescents http://www.ohchr.org/Documents/Issues/Women/WRGS/Health/ReportHLWGhumanrights-health.pdf

UNHRC, ‘Andorra' 2010 A/HRC/13/16, para 84.66

Office of the High Commissioner for Human Rights, 'Universal Periodic Review' <www.ohchr.org/en/hrbodies/upr/pages/uprmain.aspx. $>$ accessed $31^{\text {st }}$ August 2015. 
Zwart T (2012) Using Local Culture to Further the Implementation of International Human Rights: The Receptor Approach. Human Rights Quarterly 32: 546 - 569 


\begin{tabular}{|c|c|c|c|c|c|c|c|}
\hline 1 & & $\begin{array}{c}\text { A1 } \\
\text { (Accepted recommendation } \\
\text { with no further comments) }\end{array}$ & \begin{tabular}{l}
\multicolumn{1}{c}{ A2 } \\
(Domestic \\
laws already \\
implemented/ \\
under review)
\end{tabular} & \begin{tabular}{l}
\multicolumn{1}{c}{ A3 } \\
(Information on \\
measures and \\
policies that are \\
already in place)
\end{tabular} & $\begin{array}{c}\text { A5 } \\
\text { (Recognition of } \\
\text { cultural barriers) }\end{array}$ & $\begin{array}{c}\text { N1 } \\
\text { (Noted } \\
\text { recommendations } \\
\text { with no further } \\
\text { comments) }\end{array}$ & \begin{tabular}{l}
\multicolumn{1}{c}{$\mathbf{N 2}$} \\
(Policies already in \\
place)
\end{tabular} \\
\hline \multirow[t]{3}{*}{$\begin{array}{l}\text { Nature of } \\
\text { Recomme } \\
\text { ndations } \\
\text { issued to } \\
\text { states } \\
\text { under } \\
\text { review }\end{array}$} & $\begin{array}{l}\text { Recommendation } 1 \\
\text { (Generic } \\
\text { recommendations on } \\
\text { access to health care } \\
\text { services) }\end{array}$ & $\begin{array}{l}\text { Bangladesh/Benin/ } \\
\text { Canada /Costa Rica/Cuba/ } \\
\text { Democratic Republic of } \\
\text { Congo/Dominican Republic } \\
\text { /Equatorial } \\
\text { Guinea/Iran/Laos/Libya/Mala } \\
\text { wi/Niger/Sao Tome and } \\
\text { Principe/Senegal/Sierra Leone } \\
\text { /Syria/Tanzania/Thailand/Tog } \\
\text { o/Turkey/Venezuela/Viet } \\
\text { Nam/Yemen. }\end{array}$ & Afghanistan & $\begin{array}{l}\text { Afghanistan/Bolivia/E } \\
\text { ISalvador/Romania/A } \\
\text { rmenia } \\
\text { Laos/Macedonia/Na } \\
\text { mibia/Sao Tome } \\
\text { /Seychelles/Sierra } \\
\text { Leonne/Thailand }\end{array}$ & & $\begin{array}{l}\text { Suriname } \\
\text { Malta } \\
\text { Mexico }\end{array}$ & $\begin{array}{l}\text { Bosnia and } \\
\text { Herzegovina }\end{array}$ \\
\hline & $\begin{array}{l}\text { Recommendation } \mathbf{2} \\
\text { (Amend/Reform/Implem } \\
\text { ent law to protect } \\
\text { women's rights to access } \\
\text { health care services) }\end{array}$ & $\begin{array}{l}\text { Angola/Nicaragua/Timor } \\
\text { Leste }\end{array}$ & & El Salvador & Paraguay & & \\
\hline & $\begin{array}{l}\text { Recommendation } \mathbf{3} \\
\text { (References to states' } \\
\text { international } \\
\text { obligations) }\end{array}$ & $\begin{array}{l}\text { Belize/Spain/Burkina } \\
\text { Faso/Guinea/Gambia } \\
\text { /Guatemala/Saudi Arabia. }\end{array}$ & & & & Israel & \\
\hline
\end{tabular}

Figure 1: Discussions held on Women's Right to Health Care in the First Cycle of the UPR process 


\begin{tabular}{|c|c|c|c|c|c|c|}
\hline \multirow{2}{*}{\multicolumn{2}{|c|}{$\begin{array}{l}\text { Universal Periodic Review Cycle } \\
2\end{array}$}} & \multicolumn{5}{|c|}{ Responses by the states under review } \\
\hline & & $\begin{array}{c}\text { S1 } \\
\text { (Accepted recommendation } \\
\text { with no further comments) }\end{array}$ & $\begin{array}{l}\text { S2 } \\
\text { (Information on measures and } \\
\text { policies that are already in } \\
\text { place) }\end{array}$ & $\begin{array}{c}\text { N1 } \\
\text { (Noted } \\
\text { recommendations } \\
\text { with no further } \\
\text { comments) }\end{array}$ & $\begin{array}{c}\text { N2 } \\
\text { (Policies already in } \\
\text { place) }\end{array}$ & $\begin{array}{c}\text { N3 } \\
\text { (Denial of any } \\
\text { discrimination on grounds } \\
\text { of gender) }\end{array}$ \\
\hline \multirow[t]{2}{*}{$\begin{array}{l}\text { Nature of } \\
\text { Recommendati } \\
\text { ons issued to } \\
\text { states under } \\
\text { review }\end{array}$} & $\begin{array}{l}\text { Recommendation } 1 \\
\text { (Generic } \\
\text { recommendations on } \\
\text { access to health care } \\
\text { services) }\end{array}$ & $\begin{array}{l}\text { Afghanistan/Albania/Andorra/C } \\
\text { roatia/Cyprus/DPR } \\
\text { Korea/Democratic Republic of } \\
\text { Congo/Ecuador/EI } \\
\text { Salvador/Ethiopia/Guinea/Iran/ } \\
\text { Kyrgystan/Malawi/Malaysia/Ne } \\
\text { pal/Niger/Republic of } \\
\text { Congo/Romania/Saudi } \\
\text { Arabia/Somalia/St Vincent and } \\
\text { the Grenadines/Yemen }\end{array}$ & $\begin{array}{l}\text { Benin/Central African } \\
\text { Republic/Chile/Comoros/Gam } \\
\text { bia/Georgia } \\
\text { /Hungary/Lesotho/Macedonia } \\
\text { /Madagascar/Maldives/Micro } \\
\text { nesia } \\
\text { Morocco/Namibia/Peru/Philip } \\
\text { pines/Senegal /Sierra } \\
\text { Leone/Singapore/Tajikistan/T } \\
\text { hailand/Uzbekistan }\end{array}$ & Lebanon & $\begin{array}{l}\text { Antiqua and } \\
\text { Barbuda } \\
\text { Papua New Guinea }\end{array}$ & Kuwait \\
\hline & $\begin{array}{l}\text { Recommendation } 2 \\
\text { (Amend/Reform/Impl } \\
\text { ement law to protect } \\
\text { women's rights to } \\
\text { access health care } \\
\text { services) }\end{array}$ & & Bangladesh & & Nicaragua & Myanmar \\
\hline
\end{tabular}

Figure 2: Discussions held on Women's Right to Health Care in the Second Cycle of the UPR process 


1
2
3
4
5
6
7
8
9
10
11
12
13
14
15
16
17
18
19
20
21
22
23
24
25
26
27
28
29
30
31
32
33
34
35
36
37
38
39
40
41
42
43
44
45
46
47
48
49
50
51
52
53
54
55
59

